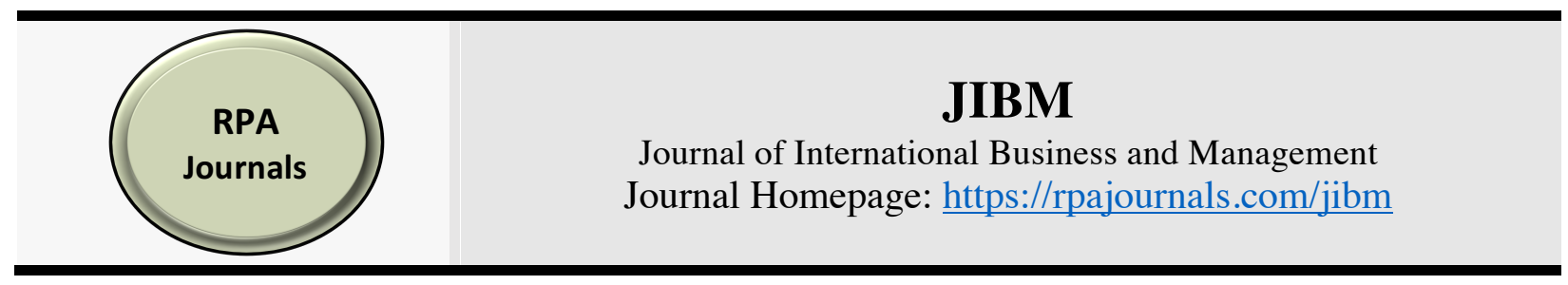

\title{
GDPR consent pop-ups. How are we thinking about them? An Elaboration Likelihood perspective
}

\author{
Corina Cara" \\ Lorena Florentina Dumitrașciuc \\ Alexandru Ioan Cuza University Iasi, Romania'
}

\begin{abstract}
Europe's General Data Protection Regulation (GDPR) led to some substantial changes to the overall user experience, one of it being the usage of pop-ups for cookie consent. One issue that emerged from this practice is the constant interruption of the users while they are browsing websites. The purpose of this paper is to determine how those popups are perceived by the regular user, using the concept of elaboration likelihood, that states that people can process information in 2 different ways, either centrally (carefully thinking about the information) or peripherally (attitudes are based on superficial elements). We used 3 dimensions for measuring elaboration - Interest, Awareness and Cognitive Engagement. We conducted a Confirmatory Factor Analysis and the results were used for predicting the habit of changing the default settings of the cookie consent pop-ups and for correlation check with other variables. We found out that Cognitive Engagement is not a significant variable for predicting the behaviour of changing the defaults, while Interest and Awareness about the subject are significant predictors. The main implications of this study lead to a broader discussion about this practice and makes us wonder if the pop-up is the best solution to ask for cookie consent.
\end{abstract}

Keywords: GDPR, Cookie Consent, User Experience, Usability, Pop-Ups, Elaboration Likelihood Model, Data Privacy

*Corresponding author: Corina Cara; Email: corina.cara@gmail.com

DOI: https://doi.org/10.37227/jibm-2020-03-14

\section{Introduction}

GDPR (General Data Protection Regulation) enforcement led to some substantial changes to the overall user experience when browsing websites (Krebs, et al., 2019), one of them being the usage of pop-ups. Pop-ups, also known as pop-overs or modal boxes are included in websites with the purpose of informing users and asking consent about the personal data that it's stored in the browser (through small files, generally known as cookies). Internet cookies are associated with pop-ups, spam and other questionable internet practices (Palmer, 2005). While the GDPR regulation was much needed from the user's rights perspective, the way it's implemented right now raises some issues, as the design is often not optimal from a user's perspective (Gröndahl, 2020). Transmitting a message through a pop-up is not the best way to do it, since users are easily annoyed with this type of graphical element (Bahr and Ford, 2011). Cookie consent pop-ups are not easy to avoid on mobile. You can avoid them to some extent on desktop, depending on how they are created. And while not avoiding 
them it's the desired behaviour, some experts are raising concerns about the effectiveness of these elements, fearing that it might have the opposite effect - users being fatigued with the notifications (Utz, et al., 2019) or ignoring the consent form.

The purpose of this research is to investigate the perception of the GDPR consent pop-ups using the theoretical framework of Elaboration Likelihood Model. Hence, the research questions of the study are:

- Does the theoretical framework of Elaboration Likelihood Model applies to the topic of GDPR pop-ups perception?

- How can the habit of changing the default settings of cookie usage pop-ups be predicted by the elaboration factors?

- How does the elaboration factors correlate with the perception of desirability, intrusiveness, utility and annoyingness of the GDPR consent pop-ups?

\section{Literature Review}

GDPR stands for General Data Protection Regulation and it is an European low implemented in 2018. Its aim is to change the way personal data is collected and processed and to give users that are living in the Greater European Economic Area more control over their data on the internet. GDPR cookie consent is mandatory in the Greater European economic Area. Cookies are referred to technologies that are used for automatically collect information about the users. Internet cookies (or browser cookies) are small dimension files that are stored on the users' devices. Cookies are primarily used for finding valuable insights about the users for business purpose. They are also used for advertising purposes, creating detailed profiles about the users. Cookies are essentially harmless, but they also raise some privacy concerns since they are storing personal information about the users and their behaviour. Since 2000, disclosure towards the users about cookie usage has increased (Miyazaki, 2008), and we can say that the GDPR regulation that came in 2018 was a natural continuity of this trend of transparency on how personal data is used on the internet.

User's rights to privacy is not necessarily a value for the most websites, as in 2017, in Europe, $49 \%$ of them did not respect the European Union Directive that introduced a first set of regulations in 2002 (Trevisan, Traverso, Bassi \& Mellia 2019). A study regarding the GDPR cookie consent compliance found out that $54 \%$ of the websites violate in a way or another the GDPR regulation (Matte, Bielova \& Santos, 2019). The GDPR regulation states that users have to give consent about cookie usage when entering a website. They also have the right to access the website even if consent is denied. The users can change whenever they want their cookie preferences. These conditions of GDPR are a step towards the right direction regarding users' rights (Politou, Alepis \& Patsakis, 2018). Even if everybody acknowledges that this regulation was extremely needed, there are studies that state that in fact, it is very difficult for an user to avoid being tracked by cookies (Sanchez-Rola, Dell'Amico, Kotzias, Balzarotti, Bilge, Vervier, \& Santos, 2019).

The consent pop-ups are without a doubt elements that help with the users inclusion in the data privacy issue. But somehow, websites are still using "dark patterns" in the process of collecting data consent (Soe, Nordberg, Guribye \& Slavkovik, 2020) - different tricks are used to manipulate the user to proceed with a certain action that is not necessary in his favour. Websites do not always design those consent pop-ups with the purpose of helping the users to make free and informed choices (Utz, Degeling, Fahl, Schaub \& Holz, 2019). The way the websites design those elements deceive users into giving consent to more cookie data storage than they intend to (Machuletz \& Böhme, 2020). In spite of the GDPR, websites are still using dark patterns for tricking the users, in 2020 only $11.8 \%$ meet the minimal requirements (Nouwens, Liccardi, Veale, Karger \& Kagal, 2020).

Pop-ups, as interface design elements, are not the best way to send the message to an user. Users tend to ignore pop-ups (Buck, Khan, Fagan \& Coman, 2018). These type of elements tend to create a high level of annoyance when are utilized to transmit a message (Bahr \& Ford, 2011). One could argue that even if in this case pop-ups are not used as a medium to advertise something, but as a meaning of informing, the effect is the same. To support this statement, we could name the numerous examples of cookie consent blocker software available to download. Related research 
work on the cookie consent pop-ups has shown that users tend to manifest a rather negative perception about it, perceiving them as nuisance or even as a threat to their privacy (Kulyk, Hilt, Gerber \& Volkamer, 2018). These findings are particularly interesting when we think about the elaboration likelihood perspective. In order to provide real protection for the users' data, these consent forms should be carefully implemented from a design point of view (Wachter, 2018).

Elaboration Likelihood Model (Petty, Cacioppo, 1986) is a dual process model that states that attitudes about something are formed on a continuum called elaboration, varying from peripheral to central, depending on how much we are thinking about a message. Central processing (when we have high levels of elaboration) means that persuasion is formed based on the careful evaluation of the information and arguments transmitted by the message. Peripheral processing (when we have low levels of elaborations) leads to a superficial persuasion that is formed by associating the message with various stimuli that are not directly related to the main message.

\section{Research Methodology}

The sample consists of users that are used to browse websites on a regular basis, for both professional and recreational purposes, aged 18 to 35 years old. They are typical users of the Internet. We used the convenience sampling method. We used 35 subjects for the pre-testing of the questionnaire and 315 subjects for the main study (we collected 346 responses but we had a number of 31 duplicate answers, which were later removed). We conducted an online survey via Facebook Ads. The ad was targeted towards 18-35 years old, all genders, enrolled in university or having higher degrees. We chose this age interval because we were looking for participants that are internet-savvy. We also wanted people with higher education to increase the possibility of them having a better knowledge about the GDPR issue.

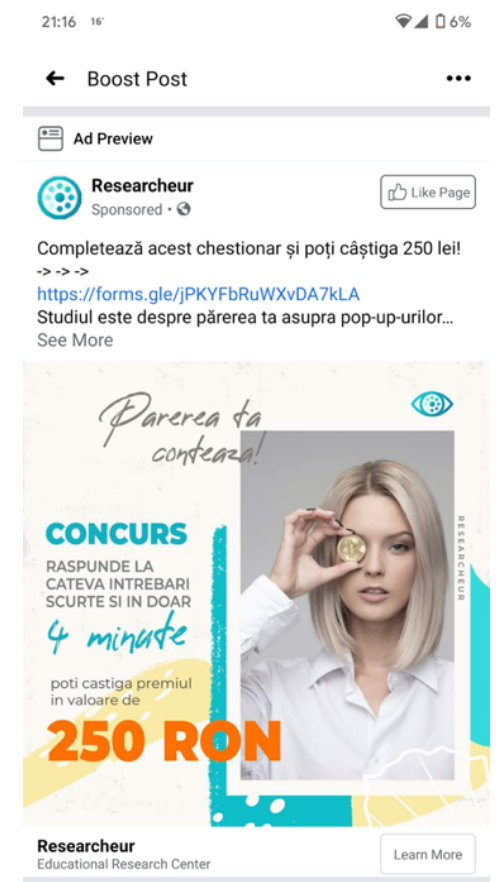

Figure 1 The Facebook Ad that was used for conducting the survey

The Figure 1 shows the ad we promoted. The survey was conducted on 25-30 May 2020. We also used a small incentive (they had the chance of winning a prize after filling out the survey). The survey post reached over 9000 users, and had over 600 engagements. We used as an instrument a questionnaire that was pre-tested on 35 subjects. After the pre-testing was conducted, 8 items were modified, 2 items were found redundant and were removed. We measured elaboration using a conceptualization developed by Vezeau (Vezeau et al., 2017) that was used in other research about 
attitude formation, such as Miller et al. (2018), from which we adapted the scale for measuring elaboration.

Elaboration was measured using three dimensions: Awareness, Interest and Cognitive Engagement.

Interest is the desire of wanting to learn about data privacy. Included 2 items (recorded on a 5-point Likert scale): The question asked was "When it comes to personal data on the internet, how interested are you in finding out about the following":

Item 1: How to keep my personal data as private as possible;

Item 2: What actions should I take to keep my personal data private when I enter a website. Awareness is defined as the general knowledge about GDPR data privacy regulation. Included 2 items (recorded on a 5-point Likert scale). The question asked was "How aware are you of":

Item 1: Ways to increase the privacy of my personal data online;

Item 2: The fact that you have different options on what kind of data the site you are browsing can store.

We define Cognitive Engagement as the amount of effort spent thinking about the pop-ups 3 items (recorded on a 5-point Likert scale): The question asked was "When you see a GDPR pop-up, how much do you think about the following"?

Item 1: The fact that the consent pop-up is meant to help me;

Item 2: The fact that I can change the default options offered by the website;

Item 3: The fact that my data is safe when I press the accept button.

Other items used (also measured on 5-point Likert scale) are: the habit of changing the default popup settings, desirability, utility, intrusiveness, and annoyingness.

\section{Results and Analysis}

We used Onyx and SPSS for analysing the data. sample consisted of $84 \%$ females and $16 \%$ males. The favourite medium of browsing is mobile for $79 \%$ and desktop for $21 \%$.

\section{Measurement model for elaboration's dimensions}

Firstly, we tested the internal consistency for each dimension. The results are provided in Table 1. For all 3 dimensions of elaboration the Cronbach's Alpha statistic is larger than 0.8 , which indicates a good internal consistency.

Table 1 Internal consistency for the dimensions of elaboration

\begin{tabular}{|c|c|c|c|c|c|c|c|c|}
\hline \multicolumn{3}{|l|}{ Interest } & \multicolumn{3}{|c|}{ Awareness } & \multicolumn{3}{|c|}{ Cognitive Engagement } \\
\hline $\begin{array}{l}\text { Cronbach' } \\
\text { s Alpha }\end{array}$ & $\begin{array}{l}\text { Cronbach's } \\
\text { Alpha } \\
\text { Based on } \\
\text { Standardize } \\
\text { d Items }\end{array}$ & $\begin{array}{l}\mathrm{N} \text { of } \\
\text { item } \\
\mathrm{s}\end{array}$ & $\begin{array}{l}\text { Cronbach' } \\
\text { s Alpha }\end{array}$ & $\begin{array}{l}\text { Cronbach's } \\
\text { Alpha } \\
\text { Based on } \\
\text { Standardize } \\
\text { d Items }\end{array}$ & $\begin{array}{l}\mathrm{N} \text { of } \\
\text { item } \\
\mathrm{s}\end{array}$ & $\begin{array}{l}\text { Cronbach' } \\
\text { s Alpha }\end{array}$ & $\begin{array}{l}\text { Cronbach's } \\
\text { Alpha } \\
\text { Based on } \\
\text { Standardize } \\
\text { d Items }\end{array}$ & $\begin{array}{l}\mathrm{N} \text { of } \\
\text { item } \\
\mathrm{s}\end{array}$ \\
\hline .911 & .911 & 2 & .883 & .883 & 2 & .852 & .852 & 3 \\
\hline
\end{tabular}

\section{CFA Model}

Furthermore, we proceeded to create a model through Confirmatory Factor Analysis. The visual depiction that includes the parameter estimates, covariances and error terms is shown in Figure 2. 


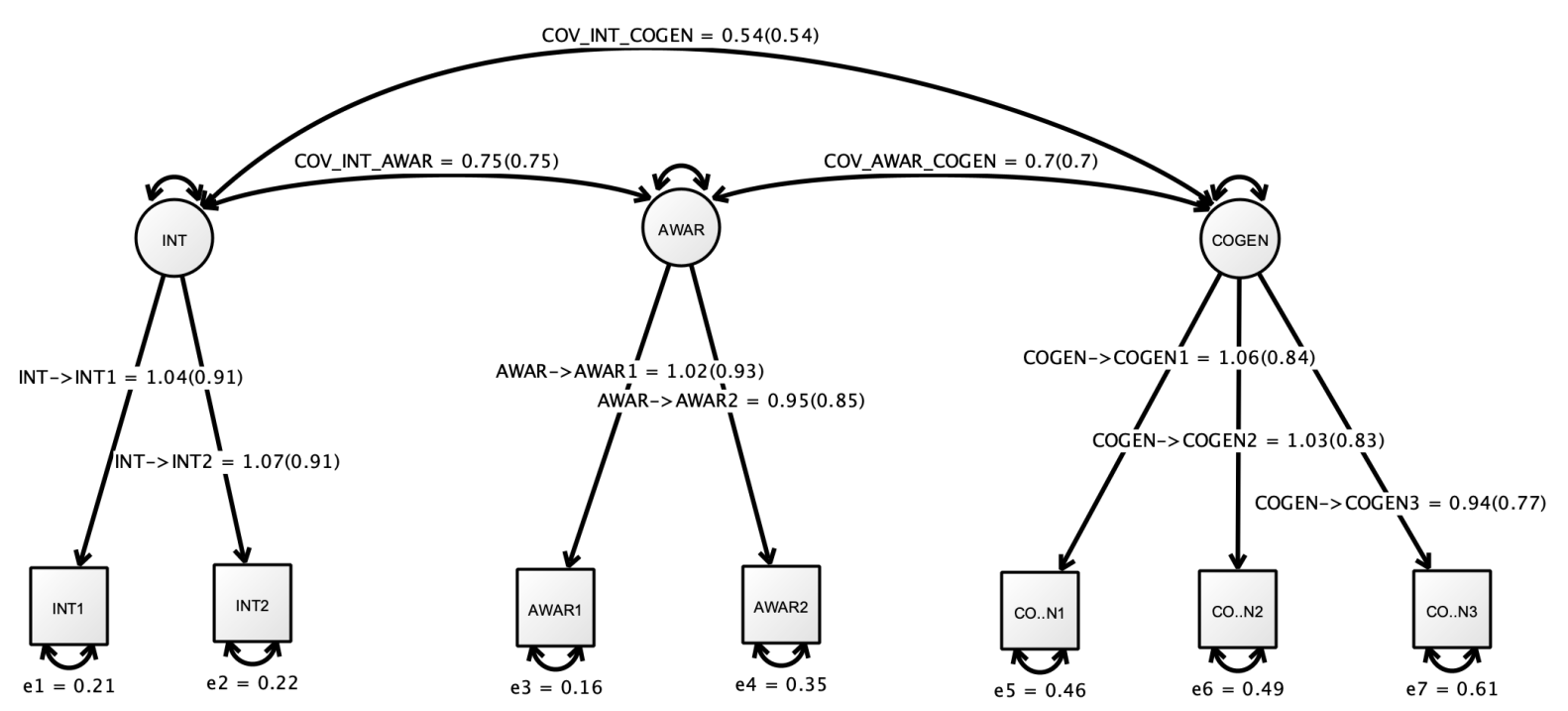

\section{Model fit indices}

Figure 2 CFA model for elaboration's dimensions

The statistics indicated a good fit for the model. The results are shown in Table 2. The ratio between Chi Square and the degrees of freedom is smaller than 3, which indicates a good fit. The p-value of the model is greater than .05 , thus the estimates are significant. The CFI and SRMR values indicate a good fit. The RMSEA value indicates a moderately good fit.

Table 2 Fit indices for the elaboration model

\begin{tabular}{|l|l|}
\hline Chi square / df & 2.709 \\
\hline p-value & $>.05$ \\
\hline CFI & .987 \\
\hline SRMR & .023 \\
\hline RMSEA & .074 \\
\hline
\end{tabular}

\section{Predicting the habit of changing the defaults}

Furthermore, we saved the factor scores as new variables. We used the scores from the Confirmatory Factor Analysis to predict the habit of changing the defaults settings of the pop-ups.

From the 3 dimensions of elaboration, Cognitive Engagement did not have a significant contribution to the model and was removed. We conduct a linear regression analysis with the other 2 dimensions. Table 3 depicts the model summary. Awareness and Interest explain together $6.6 \%$ of the variance of the behaviour of changing the defaults. The Anova result (Table 4) is statistically significant, which means that overall, the outcome variable is predicted well by Awareness and Interest.

Table 3 Model Summary

\begin{tabular}{|c|c|c|c|c|}
\hline Model & R & R Square & Adjusted R Square & $\begin{array}{c}\text { Std. Error of the } \\
\text { Estimate }\end{array}$ \\
\hline 1 & .258 & .066 & .060 & 1.32957 \\
\hline a. Predictors: (Constant), AWAR, INT
\end{tabular}


Table 4 ANOVA

\begin{tabular}{|l|l|c|c|c|c|c|}
\hline \multicolumn{2}{|l|}{ Model } & $\begin{array}{c}\text { Sum of } \\
\text { Squares }\end{array}$ & Df & $\begin{array}{c}\text { Mean } \\
\text { Square }\end{array}$ & F & Sig. \\
\hline \multirow{2}{*}{1} & Regression & 39.209 & 2 & 19.605 & 11.090 & $.000^{\circ}$ \\
\cline { 2 - 7 } & Residual & 551.540 & 312 & 1.768 & & \\
\cline { 2 - 7 } & Total & 590.749 & 314 & & & \\
\hline \multicolumn{2}{|l|}{ a. Dependent Variable: OptionsModifications } & \\
\hline \multicolumn{2}{|l|}{ b. Predictors: (Constant), AWAR, INT }
\end{tabular}

In the Table 5 we have the coefficients of the model. We can see that they are statistically significant (sig. value is smaller than .05).

Table 5 Coefficients

\begin{tabular}{|l|l|r|r|r|r|r|}
\hline \multicolumn{2}{|l|}{ Model } & $\begin{array}{c}\text { Unstandardized } \\
\text { B }\end{array}$ & $\begin{array}{c}\text { Coefficients } \\
\text { Std. Error }\end{array}$ & $\begin{array}{c}\text { Standardized } \\
\text { Coefficients } \\
\text { Beta }\end{array}$ & $\mathrm{t}$ & \multicolumn{1}{c|}{ Sig. } \\
\hline \multirow{3}{*}{1} & (Constant) & 2.387 & .075 & & 31.868 & .000 \\
\cline { 2 - 7 } & INT & -.466 & .133 & -.326 & -3.500 & .001 \\
\cline { 2 - 7 } & AWAR & .625 & .134 & .437 & 4.683 & .000 \\
\hline \multicolumn{2}{|l|}{ a. Dependent Variable: Options Modifications } \\
\hline
\end{tabular}

The model obtained is:

Habit of changing defaults $=2.387-0.466 *$ Interest $+0.625 *$ Awareness $+e$

We can conclude that the Interest has a negative contribution to the behaviour of changing the popup defaults for cookie consent, while the Awareness has a positive contribution.

We also used factor scores to see how they correlate with other variables we measured in this research. The results are shown in Tables 6, 7, 8 and 9. The desirability of consent pop-ups has no significant correlation with Interest or Awareness but has a small direct correlation with Cognitive Engagement. Intrusiveness of the pop-ups has no significant correlation with Interest or Awareness and has a small direct correlation with Cognitive Engagement. Utility of the pop-ups has no significant correlation with Interest, but has a very small direct correlation with Awareness and a small direct correlation with Cognitive Engagement. Lastly, the Perception of annoyingness regarding the consent pop-ups had a very small direct correlation with Awareness, no significant correlation with Interest and a small direct correlation with Cognitive Engagement.

Table 6 Correlation with Desirability

\begin{tabular}{|c|c|}
\hline Variable & $\begin{array}{c}\text { Significant } \\
\text { Pearson } \\
\text { Correlation }\end{array}$ \\
\hline Interest & - \\
\hline Awareness & - \\
\hline Cognitive & .292 \\
Engagement & \\
\hline
\end{tabular}

Table 7 Correlation with Intrusiveness 


\begin{tabular}{|c|c|}
\hline Variable & $\begin{array}{c}\text { Significant } \\
\text { Pearson } \\
\text { Correlation }\end{array}$ \\
\hline Interest & - \\
\hline Awareness & - \\
\hline $\begin{array}{c}\text { Cognitive } \\
\text { Engagement }\end{array}$ & .312 \\
\hline
\end{tabular}

Table 8 Correlation with Utility

\begin{tabular}{|c|c|}
\hline Variable & $\begin{array}{c}\text { Significant } \\
\text { Pearson } \\
\text { Correlation }\end{array}$ \\
\hline Interest & - \\
\hline Awareness & .150 \\
\hline $\begin{array}{c}\text { Cognitive } \\
\text { Engagement }\end{array}$ & .375 \\
\hline
\end{tabular}

Table 9 Correlation with Annoyingness

\begin{tabular}{|c|c|}
\hline Variable & $\begin{array}{c}\text { Significant } \\
\text { Pearson } \\
\text { Correlation }\end{array}$ \\
\hline Interest & - \\
\hline Awareness & .132 \\
\hline $\begin{array}{c}\text { Cognitive } \\
\text { Engagement }\end{array}$ & .367 \\
\hline
\end{tabular}

\section{Implications and Concluding Remarks}

This research contributes to the better understanding of how we perceive those pop-ups, as GDPR user experience elements. The way users elaborate upon the consent pop-ups was analysed from the perspective of Interest, Awareness and Cognitive Engagement. Altogether, this research contributes to the literature on perception of pop-ups, as user experience elements. We analysed in depth the perceptions of GDPR consent pop-ups, using the concept of elaboration from Elaboration Likelihood Model. This research is also useful for practitioners, especially for those who are directly involved in the design of the GDPR notifications. Assuring the best interest of users' data is an important value of the European Union, this paper helps to identify if the pop-up usage is the best way to do that. Therefore, the paper can also be valuable for European Institutions that are in charge with the protection of the users' best interest regarding the cookie usage, while not hindering the overall user experience.

This research aimed to explore the way individuals perceive the GDPR cookie consent popups. We measured 3 dimensions of elaboration, using the theoretical framework of the Elaboration Likelihood Model. We found out that Interest and Awareness contribute to the prediction of the behaviour of changing the defaults for the cookie consent pop-ups, while cognitive engagement is not significant in that matter. Interest has a negative contribution to the behaviour of changing the defaults, while Awareness has a positive one. In other words, when the interest about GDPR cookie usage is low, but the awareness of the subject is high, there is higher chance of changing those defaults. There were found several different significant correlations between the elaboration factors and other variables.

The data was collected through a survey, thus it represents the self-reported perception that could be slightly biased in comparison to the actual behaviour of changing the default settings of the 
consent pop-ups. We also want to mention the lack of diversity of the group, regarding the age and education. For future research, we could include subjects from other age groups and other educational backgrounds and could compare the results. We could also investigate further why the interest has a negative predictability on the behaviour of changing the defaults through an experiment.

\section{Acknowledgement}

This work was co-funded by the European Social Fund, through Operational Programme Human Capital 2014-2020, project number POCU/380/6/13/123623, project title $<<\mathrm{PhD}$ Students and Postdoctoral Researchers Prepared for the Labour Market!>>

\section{References}

Bahr, G. S., \& Ford, R. A. (2011). How and why pop-ups don't work: Pop-up prompted eye movements, user affect and decision making. Computers in Human Behavior, 27(2), 776783.

Buck, R., Khan, M., Fagan, M., \& Coman, E. (2018). The user affective experience scale: A measure of emotions anticipated in response to pop-up computer warnings. International Journal of Human-Computer Interaction, 34(1), 25-34.

European Parliament and Council of European Union (2016) Regulation (EU) 2016/679. Available at:

https://eur-lex.europa.eu/legalcontent/EN/TXT/HTML/?uri=CELEX:32016R0679\&from=EN (Accessed: 14 May 2020)

Gröndahl, L. (2020). Public knowledge of digital cookies: Exploring the design of cookie consent forms; Digitala Vetenskapliga Arkivet

Interactive Advertising Bureau Europe. 2019. GDPR Transparency and Consent Framework. https://iabtechlab.com/standards/gdpr-transparency-and-consent-framework/. [Online; accessed 13 May 2020].

Krebs, L. M., Alvarado Rodriguez, O. L., Dewitte, P., Ausloos, J., Geerts, D., Naudts, L., \& Verbert, K. (2019, May). Tell me what you know: GDPR implications on designing transparency and accountability for news recommender systems. In Extended Abstracts of the 2019 CHI Conference on Human Factors in Computing Systems (pp. 1-6).

Kulyk, O., Hilt, A., Gerber, N., \& Volkamer, M. (2018). this website uses cookies": Users' perceptions and reactions to the cookie disclaimer. In European Workshop on Usable Security (EuroUSEC).

Machuletz, D., \& Böhme, R. (2020). Multiple purposes, multiple problems: A user study of consent dialogs after GDPR. Proceedings on Privacy Enhancing Technologies, 2020(2), 481-498.

Matte, C., Bielova, N., \& Santos, C. (2019). Do Cookie Banners Respect my Choice? Measuring Legal Compliance of Banners from IAB Europe's Transparency and Consent Framework. arXiv preprint arXiv:1911.09964.

Miller, Z. D., Freimund, W., \& Powell, R. B. (2018). Measuring elaboration and evaluating its influence on behavioral intentions. J. Interpret. Res, 23, 27-44.

Miyazaki, A. D. (2008). Online privacy and the disclosure of cookie use: Effects on consumer trust and anticipated patronage. Journal of Public Policy \& Marketing, 27(1), 19-33.

Nouwens, M., Liccardi, I., Veale, M., Karger, D., \& Kagal, L. (2020, April). Dark patterns after the GDPR: Scraping consent pop-ups and demonstrating their influence. In Proceedings of the 2020 CHI Conference on Human Factors in Computing Systems (pp. 1-13).

Palmer, D. E. (2005). Pop-ups, cookies, and spam: toward a deeper analysis of the ethical significance of internet marketing practices. Journal of business ethics, 58(1-3), 271-280.

Petty, R. E., \& Cacioppo, J. T. (1986). The elaboration likelihood model of persuasion. In Communication and persuasion (pp. 1-24). Springer, New York, NY.

Politou, E., Alepis, E., \& Patsakis, C. (2018). Forgetting personal data and revoking consent under the GDPR: Challenges and proposed solutions. Journal of Cybersecurity, 4(1), tyy001. 
Sanchez-Rola, I., Dell'Amico, M., Kotzias, P., Balzarotti, D., Bilge, L., Vervier, P. A., \& Santos, I. (2019, July). Can I Opt Out Yet? GDPR and the Global Illusion of Cookie Control. In Proceedings of the 2019 ACM Asia Conference on Computer and Communications Security (pp. 340-351).

Soe, T. H., Nordberg, O. E., Guribye, F., \& Slavkovik, M. (2020). Circumvention by design--dark patterns in cookie consents for online news outlets. arXiv preprint arXiv:2006.13985.

Trevisan, M., Traverso, S., Bassi, E., \& Mellia, M. (2019). 4 years of EU cookie law: Results and lessons learned. Proceedings on Privacy Enhancing Technologies, 2019(2), 126-145.

Utz, C., Degeling, M., Fahl, S., Schaub, F., \& Holz, T. (2019, November). (Un) informed Consent: Studying GDPR Consent Notices in the Field. In Proceedings of the 2019 ACM SIGSAC Conference on Computer and Communications Security (pp. 973-990).

Vezeau, S. L., Powell, R. B., Stern, M. J., Moore, D. D., \& Wright, B. A. (2017). Development and validation of two scales to measure elaboration and behaviors associated with stewardship in children. Environmental Education Research, 23(2), 192-213

Wachter, S. (2018). Normative challenges of identification in the Internet of Things: Privacy, profiling, discrimination, and the GDPR. Computer law \& security review, 34(3), 436-449. 